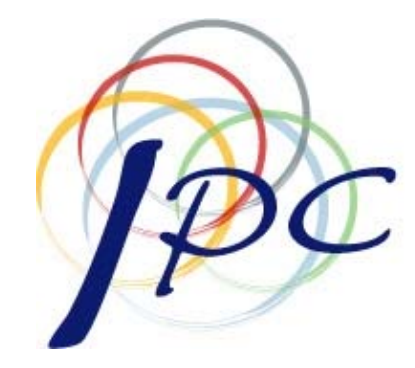

INTERNATIONAL Policy CENTER

Gerald R. Ford School of Public Policy University of Michigan

IPC Working Paper Series Number 106

Firm Heterogeneity, Informal Wage and Good Governance

Sugata Marjit

September 2010 


\title{
Firm Heterogeneity, Informal Wage and Good Governance
}

\author{
Sugata Marjit ${ }^{*}$ \\ Centre for Studies in Social Sciences, Calcutta, India \\ And \\ The Leverhulme Centre for Research in Globalization and Economic Policy \\ University of Nottingham, UK
}

September 2010

\begin{abstract}
We provide an analysis of enforcement policies applicable to informal labor market in a framework with heterogeneous firms, endogenous determination of informal wage and politically dictated strategies. We argue that firms which operate both in the formal and informal sectors do very little to increase employment when faced with the opportunity of hiring workers in the informal labor market. Thus enforcement of labor laws and other regulations should not have aggregate employment effects. For firms operating exclusively in the informal sector, the outcome is different. Such features determine the stringency of enforcement in a market characterized by firms with varying levels of productivity. For example, for firms with relatively high levels of productivity, enforcement has to be stricter than in the case with relatively low productivity firms. Taxing the more efficient seems to be the optimal strategy.
\end{abstract}

Keywords - Informal Labor, Wage, Labor Regulations, Enforcement

JEL Classification: J21, J31, J50

\section{Address for Correspondence}

\author{
Sugata Marjit \\ Centre for Studies in Social Sciences, Calcutta \\ R 1 B.P. Township \\ Calcutta- 700094 \\ India \\ (smariit@hotmail.com) (marjit@gmail.com)
}

\footnotetext{
* I am indebted to Ravi Kanbur and Jan Svejnar for comments and for the invitation to attend the conference on "Enforcement, Evasion and Informality: Theory and Practice An International Conference in Honor of Katherine Terrell” held at the University of Michigan, Ann Arbor in June 2010. The idea of this paper was conceived during a visit to Cornell University in the Summer of 2009. I acknowledge the hospitality of the Department of Applied Economics and Management. I also thank Saibal Kar for editing the manuscripts and Anindita Majumder for research assistance. The usal disclaimer applies.
} 


\section{Introduction}

Informal or unorganized labor markets absorb most of the workforce in the developing world. While workers employed in organized, i.e., the formal segment of the labor market are expected to enjoy trade union rights, and have claims on government recognized wage and other benefits, informal workers typically do not get such benefits. Consequently, they are exposed to day-to-day fluctuations of the labor market. A simple characterization of such segmented markets, that is generally accepted, runs in terms of the difference in wage rates. Formal sector workers normally enjoy higher wages than their informal counterpart.

Recent literature on informal labor market has focused on the impact of liberal economic policies on informal wage and employment. Marjit (2003), Goldberg and Pavnick (2003), Marjit, Ghosh and Biswas (2007) etc. have discussed the impact of trade policies on the size of the informal sector. In a different context Dasgupta and Marjit (2006), Marjit, Mukherjee and Kolmar (2006) have analyzed the political reasons to promote and perpetuate the existence of "informal" labor market even if such markets undermine the legal jurisdictions. A poor country can choose to look away from the 'informal' sector because it provides "social security" for the poor and prevents political unrest. These views hold under the presumption that having an informal i.e. a low wage labor market helps “employment” situation and contain poverty. Kanbur (2009) elegantly summarizes the issue on enforcement of regulation in informal markets. In particular, emphasis is given on how the states decide on the limits of enforcement. This paper draws on these observations and provides a formal model of enforcement. Papers by Bajamin et.al 
(2010), Estrin and Mickiewicz (2010) etc. elaborate the extent of compliance with regulations in different countries. One common observation in these analyses seems to be substantial evidence of lack of enforcement.

The purpose of this paper is to show, in terms of a simple framework, that existence of informal sector may not necessarily increase aggregate employment relative to a situation when there is no such sector. In other words, a change in the informal wage may not affect aggregate employment when firms employ both formal and informal workers. Employment effects of changes in informal wage will depend critically on the distribution of firms along the productivity spectrum. Degree of heterogeneity of firms matters in determining the aggregate effects of employment. ${ }^{1}$ From a political economy angle, our analysis has some new insights to offer. Since more productive firms will not increase their total demand for labor if faced with the opportunity to access informal labor market, political authorities in a democracy should be more inclined to enforce regulations in industries or markets where formal firms have large presence.

The paper is organized as follows. In the second section we develop the model and discuss the employment effects. The third section looks at the determination of informal wage. The fourth discusses policy aspect of the problem and the last section concludes.

\footnotetext{
${ }^{1}$ Firm heterogeneity has played a key role in contemporary trade theoretic work. For an elegant survey refer to Helpman (2006)
} 


\section{Equilibrium in Segmented Labor Market}

Consider an economy with firms having a choice of hiring two kinds of labor; formal and informal at predetermined wage rates $w_{1}>w_{2}, w_{1}$ being the wage paid to the formal workers and $w_{2}$ is paid to the informal workers. Labor (L) is homogeneous and difference in wage rates is the only guiding factor differentiating the formal and informal sector. But the rule of law suggests that the firms are legally bound to pay $w_{1}$ to each worker and they are liable to be punished if they do not. $w_{1}$ should be interpreted as wages plus benefits i.e. the effective hiring cost of labor in the formal market. ${ }^{2}$

Firms are distributed in a continuum indexed by $Z, Z \in[0,1]$

Production functions are given by

$\mathrm{F}=\theta(Z) f\left(L_{i}\right), \mathrm{i}=1,2$

With $\theta^{\prime}(Z)>0, \theta(0)=\underline{\theta}, \theta(1)=\bar{\theta}$ and

$$
\begin{aligned}
& f^{\prime}>0, f^{\prime \prime}<0, \\
& f(0)=0
\end{aligned}
$$

Thus firms higher up in the ladder are more productive, i.e, greater compliance with labor regulations make formal firms more productive.

Formal activities are conducted in a legal environment. Informal labor, if hired, will constitute extra legal activity. If audited and apprehended, such firms will have to pay a fine $S$. Firms hiring informal workers paying $w_{2}$ are liable to be punished if apprehended.

\footnotetext{
${ }^{2} w_{1}$ will be held fixed in the major part of the analysis while $w_{2}$ will be eventually determined with the system. Later we shall provide an outline of a method to endogenize $w_{1}$ as well.
} 
The probability of audit is $q(0<q<1)$ and the penalty function is $S$ with the following characterization:

$\mathrm{S}=\mathrm{S}\left(L_{2}\right), S^{\prime}>0, S^{\prime \prime}>0$,

The complex penalty function can be easily substituted by a constant penalty and convex audit probability $q$ with respect to the size of informal employment. The point is that, in the presence of $q \& S$ bigger firms find it increasingly difficult to operate in the informal sector.

One can interpret $S$ as perceived penalty due to loss of reputation if the issue of illegality is exposed in the media. Therefore, $S$ is essentially a loss function, however it might be interpreted. $^{3}$

Hence, the profit function of the $Z^{\text {th }}$ firm will be given by

$$
\begin{aligned}
& \pi\left(Z, L_{1}, L_{2}\right)=\theta(z) f\left(L_{1}+L_{2}\right)-w_{1} L_{1}-w_{2} L_{2}-q S\left(L_{2}\right) \\
& \frac{\partial \pi}{\partial L_{1}}=0, \text { and } \frac{\partial \pi}{\partial L_{2}}=0, \quad \text { imply } \\
& \theta(Z) f^{\prime}\left(L_{1}\right)=w_{1} \\
& \theta(Z) f^{\prime}\left(L_{2}\right)=w_{2}+q S^{\prime}\left(L_{2}\right)
\end{aligned}
$$

For determining $L_{1}, L_{2}$ equate (4) and (5):

$$
w_{1}=w_{2}+q S^{\prime}\left(L_{2}\right)
$$

Let $\tilde{L}_{2}$ solve (6)

$$
\text { Or, } \tilde{L}_{2}=\phi\left(w_{1}, w_{2}, q\right)
$$

\footnotetext{
${ }^{3}$ For related discussion refer to Marjit, Ghosh and Biswas (2007) which explicitly relates $S$ to a NashBargaining problem involving bribes and generates similar marginal cost of hiring informal workers.
} 
(7) implies that for $L>\widetilde{L}_{2}$ hiring informal workers will be more expensive on the margin. Therefore, if the firm decides to hire $L$ number of workers and $L>\widetilde{L}_{2}$, then $\left(L-\widetilde{L}_{2}\right)$ will be hired from the formal sector. If $L \leq \tilde{L}_{2}$, informal workers will be cheaper to hire.

Now, from (4)

$$
L_{1}=\phi\left(\theta(Z), w_{1}\right)
$$

It is easy to show that $\frac{\partial L_{1}}{\partial Z}>0$ as

$\theta^{\prime}>0$ and $f^{\prime \prime}<0$

Let us solve for $\tilde{Z}$ such that

$\tilde{L}_{2}=\phi\left(\theta(\tilde{Z}), w_{1}\right)$

$\tilde{Z}$ is the threshold productivity above which all firms hire formal workers along with informal workers. Those below hire only in the informal sector.

From (8) and (9) following are immediate.

Lemma 1: $\left.\forall Z>\tilde{Z},\left[L_{1}(Z)-\tilde{L}_{2}\right)\right]$ will be the extent of employment in the formal sector.

Proof: $L_{1}(\tilde{Z})=\tilde{L}_{2}, \frac{\partial L_{1}}{\partial Z}>0, \forall Z>\tilde{Z}$

Therefore, $w_{2}+q S^{\prime}\left(L_{2}\right)>w_{1} \quad$ (QED)

Lemma 2: $\forall Z \leq \tilde{Z}$, firms will not operate in the formal sector.

Proof: $\forall Z \leq \tilde{Z}, w_{2}+q S^{\prime}\left(L_{2}\right)<w_{1}$ 
So far we have been silent on the distribution of firms. Let us assume that $\eta(Z)$ represents the density function with $\int_{0}^{1} \eta(Z) d Z=1$

From Lemmas 1 and 2,

aggregate employment is given by,

$L E=\tilde{L}_{2} \int_{\tilde{Z}}^{1} \eta(Z) d Z+\int_{\tilde{Z}}^{1}\left(L_{1}(Z)-\tilde{L}_{2}\right) \eta(Z) d Z+\int_{0}^{\tilde{Z}} L_{2}(Z) \eta(Z) d Z$

Relatively productive firms $[Z \geq \tilde{Z}]$ hire both formal and informal workers. Firms $(Z \leq \tilde{Z})$ with lower productivities hire only informal workers. Rauch (1991) gets similar separation results on a different model with varying firm size.

Proposition 1: If $\eta(Z)=0 \forall Z \leq \tilde{Z}$ and $\int_{Z}^{1} \eta(Z) d Z=1$, then LE is independent of $w_{2}$.

Proof: Note that, $\tilde{L}_{2}$ depends only on $w_{1} w_{2}$, and $q$ [from (7)].Here we are considering a situation where all firms are distributed above the threshold productivity $\tilde{Z}$. From Lemma 1 and 2 we know

$$
\begin{aligned}
L E & =\int_{Z}^{1} L_{1} \eta(Z) d Z \\
& =\int_{Z}^{1} \phi\left(\theta(Z), w_{1}\right) \eta(Z) d Z
\end{aligned}
$$

which is independent of $w_{2}$. (QED)

Following observations are in order.

First, Proposition 1 implies whatever be the change in the informal wage, aggregate employment of relatively productive firms will not change as long as they use both 
formal and informal workers. They just substitute one type of employment with the other as $w_{2}$ changes.

Second, composition of employment will change as $\tilde{L}_{2}$ does respond to $w_{2}$. Employment in the formal sector is given by

$$
L_{F}=\int_{\tilde{Z}}^{1}\left(L_{1}(Z)-\tilde{L}_{2}\right) \eta(Z) d Z
$$

It is straightforward to argue that a fall in $w_{2}$ will reduce employment in the formal sector by increasing $\tilde{Z}$.

Fig -1 describes the firm level equilibrium.

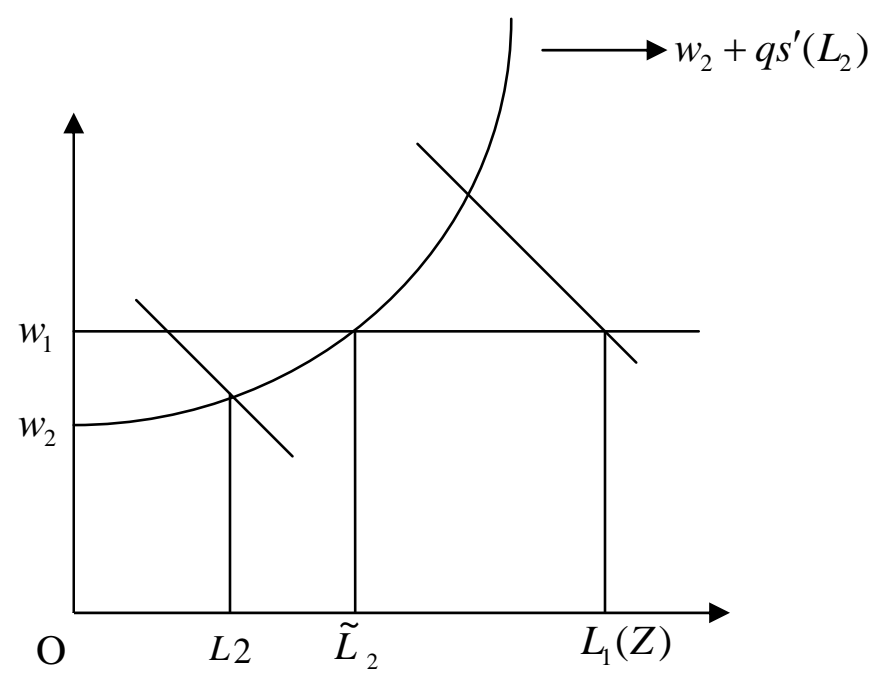

Fig-1

$\mathrm{OL}_{2}$ - Informal employment in a firm operating only in the informal sector

$L_{1}(Z)-\tilde{L}_{2}-$ Formal employment in a firm operating in both formal and informal sector. 


\section{Determination of Informal wage}

Suppose aggregate labor force is given by $\bar{L}$. People look for jobs in the informal sector if they do not find one in the formal sector, with $w_{1}>w_{2} \cdot{ }^{3}$ Therefore, effective supply of labor in the informal sector is given by

$L_{I}^{S}=\bar{L}-L_{F}$

Recall that $\tilde{Z}$ is defined by

$\theta(\tilde{Z}) f^{\prime}\left(\tilde{L}_{2}\right)=w_{1}$

Now

$\frac{d L_{F}}{d w_{2}}=-L_{1}(\tilde{Z}) \eta(\tilde{Z}) \frac{d \tilde{Z}}{d w_{2}}-\frac{d L_{2}^{2}}{d w_{2}} \int_{\tilde{Z}}^{1} \eta(Z) d Z+\tilde{L}_{2} \frac{d \tilde{Z}}{d w_{2}} \eta(\tilde{Z})$

Also $L_{1}(\tilde{Z})=\tilde{L}_{2}$

Therefore, $\frac{d L_{F}}{d w_{2}}=-\frac{\partial \tilde{L}_{2}}{\partial w_{2}} \int_{\tilde{Z}}^{1} \eta(Z) d z>0$

$\frac{d L_{I}^{S}}{d w_{2}}=\frac{d \tilde{L}_{2}}{d w_{2}} \int_{\widetilde{Z}}^{1} \eta(Z) d z<0$

If the informal wage goes up, firms switch to formal employment and more firms initially hiring only informal workers start hiring both formal and informal workers. Thus, total employment in the formal sector goes up. The residual number of jobseekers in the

\footnotetext{
${ }^{3} w_{1}$ is assumed to be given through negotiations with the trade unions, a feature of the organized labor market. Endogenous $w_{2}$ must be lower than $w_{1}$, otherwise everyone will go for informal job. While there is no explicit mechanism by which $w_{1}$ adjusts under such circumstances, we assume away such possibilities for focusing on our main interest. In the literature Agenor and Montiel (1996), Marjit (2003) and others have worked with such models. One can explicitly solve for $w_{1}$ by constructing the union's objective function to ensure $w_{1}>w_{2}$. One may also refer to Carruth and Oswald (1984) in this context. The appendox provides a sketch of a proof of how $w_{1}$ can be endogenized.
} 
formal sector goes down. In other words, the labor supply function has a negative relation with $w_{2}$.

Let $\tilde{w}_{2}$ be defined such that

$L_{2}=L_{2}\left(\tilde{w}_{2}\right)=\widetilde{L}_{2}$

$L_{F}=0$

Hence for $w_{2} \leq \widetilde{w}_{2}, L_{F}=0$

In this case $L_{I}^{s}=\bar{L}$

Suppose $w_{2} \geq w_{1}$ then all firms will hire formal workers and formal sector employment will hit the maximum level say $\bar{L}_{F}$.

We assume

$$
\bar{L}>\bar{L}_{F}
$$

(17) suggest that even the maximum level of formal sector employment will not be able to exhaust labor supply. $L_{S}^{I}$ looks $S_{1} S_{2} S_{3} S_{4}$ in Fig - 2 


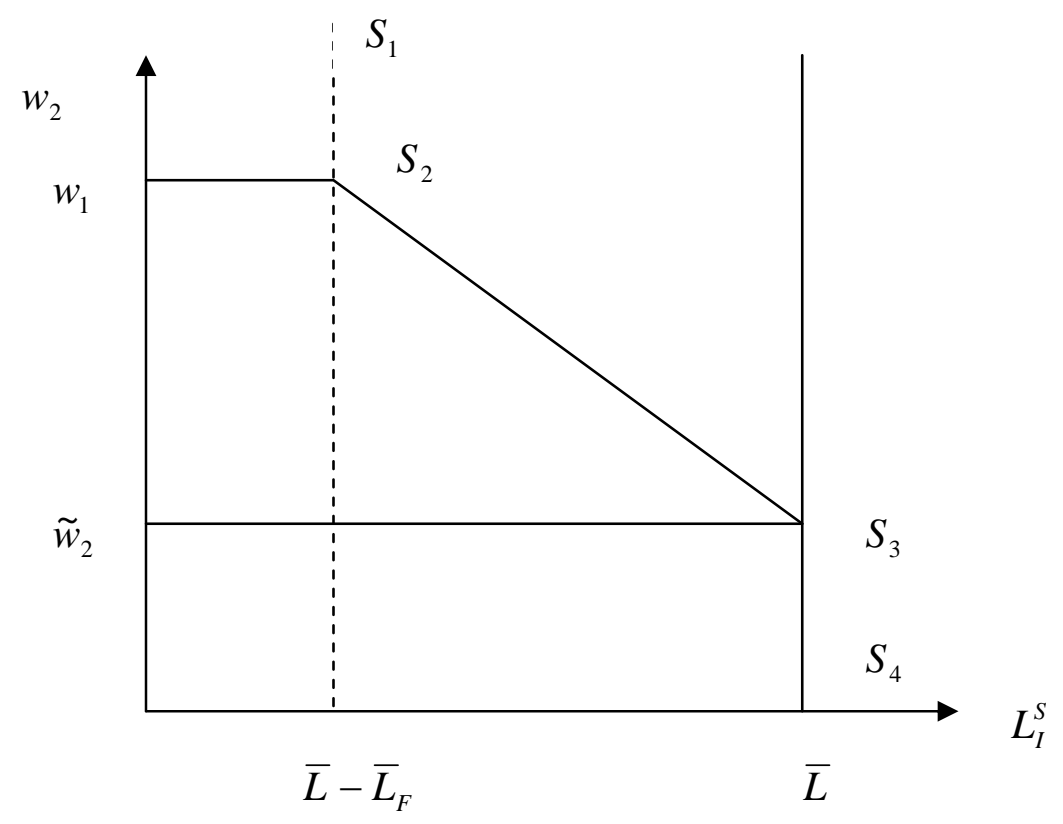

Fig-2

Aggregate demand for informal labor will decline as $w_{2}$ moves up. Let us denote the aggregate demand as $L_{I}^{D}$.

$L_{I}^{D}=0$ for $w_{2} \geq w_{1}$.

This is obvious from (6).

It is also straightforward to argue that $L_{I}^{D}$ will continue to increase with decline in $w_{2}$. Let the following be true.

$\operatorname{Lim} L_{I}^{D}\left(w_{2}\right)>\bar{L}$

$w_{2} \rightarrow 0$

(18) guarantees that for a low enough $w_{2}$ aggregate informal employment can exhaust the entire supply of labor . This will ensure a positive equilibrium $w_{2}$. 
Given the nature of demand and supply function, we can infer the following. Let $w_{2}^{*}$ be the equilibrium wage.

Proposition 2: Two possible equilibria will emerge either $w_{1}>w_{2}^{*}>\widetilde{w}_{2}$ or $w_{2}^{*} \leq \widetilde{w}_{2}$.

Proof: First, note that equilibrium always exists.

Given (18) holds such $\exists w_{2}^{*}$ such $L_{I}^{D}\left(w_{2}^{*}\right)=\bar{L}$.

Also $L_{I}^{D}\left(w_{2}^{*} \geq w_{1}\right) \leq L_{I}^{S}\left(w_{2}^{*}\right)$

Given continuity of $L_{I}^{D}, \exists w_{2}^{*}$ such that $L_{I}^{D}=L_{I}^{S}$

it is also shown that the equilibrium wage $w_{2}^{*}$ has to be less than $w_{1}$. But $w_{2}^{*}$ can be less than $\tilde{w}_{2} . \quad(\mathrm{QED})$

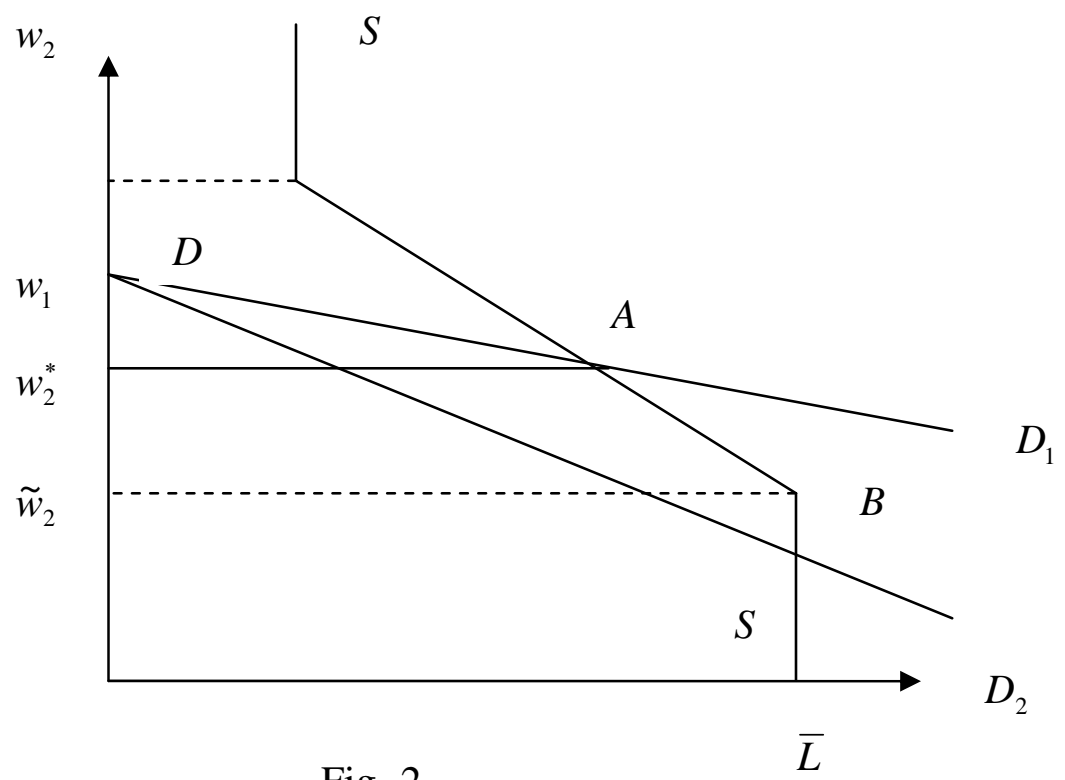

Fig- 2 
As figure3 suggests both A and B are stable equilibrium. From the definition of $\widetilde{w}_{2}$, at A there will be some employment in the formal sector. At B, there will be no formal sector employment. Also note that both A and B are Walrasian stable equilibrium. As $w_{2}$ goes down at A, better firms will increase demand for informal labor and so does the worse firms operating only in the informal sector. As better firms increase demand for labor, they retrench formal workers who then join the informal sector. So, the net employment effect for then formal firms is zero. The residual left is the increase in demand by the informal firms. So $D_{I}$ responds to a greater extent than $S_{I}$. Thus, the excess demand increases with a drop in $w_{2}$ and stability is guaranteed. Finally when $w_{1}$ is edogeneous, a rise in $w_{2}$ must rise $w_{1}$ (see the appendix) cutting back the increase in employment in the formal sector. Thus raising the supply $L_{I}$ more than in the case with exogeneous $w_{1}$. Similarly demand for $L_{I}$ falls further as $w_{1}$ also increases following a rise in $w_{2}$. Both these effects will reduce $w_{2}$ relative to $w_{2}^{*}$ when $w_{1}$ is edogeneous. Such edogeneity introduces flexibility in $w_{1}$, hurting the informal workers.

\section{Policy Issues}

In this section we are going to discuss two specific policies: one discussed in the public forum and other never discussed in the public perhaps owing to profound political implications it carries.

\section{a) Labor Market Reform}

If hiring and firing is costly, if exiting from an industry is difficult, it may hurt employment in the formal sector. These justify labor market reform policies prescribed 
for the developing countries. However, such policies are undertaken with respect to the formal sector. If one reduces effective wage cost in the formal sector, it will have some impact on the informal wage, an indicator of the purchasing power of millions of the poor people. In the set up developed so far, changes in $w_{1}$ will affect both demand and supply in the informal sector.

Consider an initial equilibrium $w_{2}^{*}$.To show what happens to $w_{2}^{*}$ subsequent to a change in $w_{1}$ we need to check the impact on $L_{I}^{D}$ relative to $L_{I}^{S}$ for a change in $w_{1}$.

Let us look at the impact on the supply side first.

From (11) we know

$$
\begin{aligned}
& L_{F}=\int_{\tilde{Z}}^{1} L_{1}(Z) \eta(Z) d Z-\int_{\tilde{Z}}^{1} \tilde{L}_{2}(Z) \eta(Z) d Z \\
& \begin{aligned}
\frac{d L_{F}}{d w_{1}} & =-L_{1}(\tilde{Z}) \eta(\tilde{Z}) \frac{d Z}{d w_{1}}-\frac{d \tilde{L}_{2}}{d w_{1}} \int_{\tilde{Z}}^{1} \eta(Z) d Z+\tilde{L}_{2} \frac{d \tilde{Z}}{d w_{1}} \eta(\tilde{Z})+L_{1}(\tilde{Z}) \eta(\tilde{Z}) \frac{d L_{1}}{d w_{1}} \\
& =-\frac{d \tilde{L}_{2}}{d w_{1}} \int_{\tilde{Z}}^{1} \eta(Z) d Z+L_{1}(\tilde{Z}) \eta(\tilde{Z}) \frac{d L_{1}}{d w_{1}}
\end{aligned}
\end{aligned}
$$

From (5) and the fact that $S^{\prime \prime}>0 \cdot \frac{d \tilde{L}_{2}}{d w_{1}}>0$ and $\frac{d L_{1}}{d w_{1}}<0$

Therefore,

$$
\frac{d L_{I}^{S}}{d w_{1}} \mid=\frac{d \tilde{L}_{2}}{d w_{1}} \int_{\tilde{Z}}^{1} \eta(Z) d Z-\int_{\tilde{Z}}^{1} \frac{d L_{1}}{d w_{1}} \eta(Z) d Z>0
$$

If $w_{1}$ goes up, formal sector employment shrinks leading to a rise in informal labor supply. If labor reform pushes $w_{1}$ down, $L_{I}^{S}$ will shift inward.

Now, $L_{I}^{D}=\int_{0}^{\tilde{z}} L_{2}(Z) \eta(Z) d Z+\int_{\tilde{Z}}^{1} \tilde{L}_{2} \eta(Z) d Z$ 


$$
\begin{aligned}
\frac{d L_{I}^{D}}{d w_{1}} & =\int_{0}^{\tilde{Z}} \frac{d L_{2}}{d w_{1}} \eta(Z) d Z-L_{2}(\tilde{Z}) \eta(\tilde{Z}) \frac{d \tilde{Z}}{d w_{1}}+\tilde{L}_{2} \eta(\tilde{Z}) \frac{d \tilde{Z}}{d w_{1}}+\int_{\tilde{Z}}^{1} \frac{d \tilde{L}_{2}}{d w_{1}} \eta(Z) d Z \\
& =\int_{\tilde{Z}}^{1} \frac{d \tilde{L}_{2}}{d w_{1}} \eta(Z) d Z
\end{aligned}
$$

Therefore combining (20) and (21) we get,

$$
\frac{d L_{I}^{D}}{d w_{1}}-\frac{d L_{I}^{S}}{d w_{1}}=\int_{\widetilde{Z}}^{1} \frac{d L_{1}}{d w_{1}} \eta(Z) d Z
$$

Since, $\frac{d L_{1}}{d w_{1}}<0, \frac{d\left(E D_{I}\right)}{d w_{1}}<0$ where $E D_{1} \equiv L_{I}^{D}-L_{I}^{S}$.

\section{Proposition 3: Since informal labor market is Walrasian stable, labor market reform will improve informal wage.}

Proof: A decline in hiring and firing cost of the organized sector labor i.e. $L_{1}$ will increase excess demand for labor in the informal labor market as

$\frac{d\left(E D_{I}\right)}{d w_{1}}<0($ from $(22))$

By Walrasian Stability $\frac{d\left(E D_{1}\right)}{d w_{2}^{*}}<0$.

Hence $w_{2}^{*}$ must rise. $\quad$ (QED)

\section{b) Political Economy of Informal Sector}

As we have already discussed the informal labor market provides employment to a vast pool of workers who do not find jobs in the so called organized formal sector. In many ways this acts as a cushion for poor people in the developing countries. But the activities which employ informal workers tend to be outside the domain of legal boundary. These transactions are often unrecorded, unregistered and overall extra legal. 
If the state has to preserve the sanctity of legal institutions and rules of law, strictly speaking, it becomes difficult to ignore informality completely and wish away extra legal activities. On the other hand, poor countries have to care for employment and income earning capacity of the huge unskilled population.

In our framework, $q$ represents an index of the monitoring intensity or stringency of the legal structure in place. Higher $q$ affects informal wage by restricting demand. If the government cares about aggregate employment as well as the importance of the legal institution, one may propose the following object function of the state.

$\Omega=\Omega(q, E)-C(q)$

With $\Omega_{1}>0, \Omega_{2}>0, \Omega_{11}<0, \Omega_{22}<0, \Omega_{12}=\Omega_{21}=0, C^{\prime}>0, C^{\prime \prime}>0$

where $C(q)$ denotes cost of preserving law or rules of law and regulatory framework.

Note that the objective of the government is related to those one used in Marjit, Kolmar and Mukherjee (2006). But in the latter the explicit role and working of the informal labor market was not introduced.In Marcoullier and Young (1995) a Leviathan State allowed informal activities or corruption to sustain itself for material gains. But ours is drawn from a more welfarist perspective.

Aggregate employment $E$ is defined as

$$
\begin{aligned}
E & \equiv \int_{0}^{\tilde{Z}} L_{2}(Z) \eta(Z) d Z+\int_{Z}^{1} \tilde{L}_{2} \eta(Z) d Z+\int_{Z}^{1}\left(L_{1}(Z)-\tilde{L}_{2}\right) \eta(Z) d Z \\
& =\int_{0}^{\tilde{Z}} L_{2}(Z) \eta(Z) d Z+\int_{\tilde{Z}}^{1} L_{1}(Z) \eta(Z) d Z
\end{aligned}
$$

One way to classify societies is to do it according to the distribution of firms.

First note that 


$$
\frac{d E}{d q}=L_{2}(\tilde{Z}) \eta(\tilde{Z}) \frac{d \tilde{Z}}{d q}+\int_{0}^{\tilde{z}} \frac{\partial L_{2}(Z)}{\partial q} \eta(Z) d Z-L_{1}(\tilde{Z}) \eta(Z) \frac{d \tilde{Z}}{d q}+\int_{\tilde{Z}}^{1} \frac{\partial L_{1}(Z)}{\partial q} \eta(Z) d Z
$$

As discussed earlier (from(4)) $q$ does not affect $L_{1}(Z)$. The only term that is relevant is given by

$$
\frac{d E}{d q}=\int_{0}^{\tilde{z}} \frac{\partial L_{2}(Z)}{\partial q} \eta(Z) d Z
$$

With $\frac{\partial L_{2}(Z)}{d q}<0$

From (26) let us define an implicit function

$$
E=E(q), E^{\prime}<0
$$

Therefore from (22) and (26) we get

$$
\begin{gathered}
\Omega=\Omega(q, E(q))-C(q) \\
\frac{d \Omega}{d q}=0 \Rightarrow \Omega_{1}+\Omega_{2} E^{\prime}-C^{\prime}=0 \\
\Rightarrow \Omega_{1}=C^{\prime}-\Omega_{2} E^{\prime}
\end{gathered}
$$

Note that the LHS represents the marginal benefit from upholding the sanctity of legal institutions, rules of law, punishing the illegal and extra legal etc. Right hand side represents the direct cost of monitoring and the indirect cost in terms of a reduction in employment in the informal sector.

Let $q^{*}$ solve (29). ${ }^{4}$

Economies may be classified in terms of quality of firms those operate in the economy. Think of a situation where all firms operate in the formal sector with $\eta(Z)=0 \forall Z<\tilde{Z}$ and

\footnotetext{
${ }^{4}$ SOC is satisfied provided $\left|\Omega_{11}-C^{\prime \prime}+\Omega_{2} E^{\prime \prime}\right|>\Omega_{2} E^{\prime \prime}$
} 
$\eta(Z)>0$ for $Z \geq \tilde{Z}$. We know that $E^{\prime}=0$ in that situation. This will imply a higher $q^{*}$ compared to where there are firms operating only in the informal sector. Since more productive firms do not change their level of employment following changes in $q$, they just substitute informal by formal, the government should not have the incentive to protect the extra legal sector because the marginal cost of implementing higher levels of $q$ is relatively low, on the other hand for firms who are operating only in the informal sector, this is an additional cost. It lowers the level of employment.

Firms which operate in formal as well as in the informal sector tend to substitute one type of employment with the other. If $q$ goes up, they will substitute informal employment with formal employment and that helps good governance. It discourages informal activities without much of an impact on aggregate employment. Thus, if either through a growth in labor productivity or through any set of factors that shift the labor demand curve upward, the need for pampering informal sector gradually declines. It follows that since the employment effect of bad governance is not so significant developed countries do not need to be protective about the informal segment.

\section{Concluding Remarks}

The paper describes the process of employment generation in the formal and informal segments of a typical industry. Firms face higher cost of hiring formal workers relative to informal workers. Given the heterogeneity of firms in terms of productivities, enforcement of minimum wage law is bound to have different employment effects acm various firms. One major result is that firms which operate in the formal as well as in the informal sector, do not contribute to total employment faced with a lower informal wage. 
Those exclusively engaged in the informal sector respond appropriately as the informal wage changes. This provides the foundation to a policy which suggests that more stringent enforcement of labor laws with respect to more productive, bigger firms is a politically sustainable policy in a developing economy. Since developed countries have far greater share of firms engaged in the formal sector, it is logical for them to strongly enforce minimum wage law. Thus our paper provides a themetical analysis of limits of enforcement.

At a theoretical level we could endogeneize informal wage and argue why informal labor market will be inherently Walrasian Stable even if the labor supply responds negatively to informal wage. Such apparatus is potentially amenable to many comparative static results. Further extensions can be done in terms of bringing in skill differentials within labor, explicit introduction of capital, uncertainty and open unemployment. 


\section{$\underline{\text { Appendix }}$}

Determination of $w_{1}$

The trade union maximizes the sum of income (u) from formal sector and also the income the union members receive as informal workers when they do not find a job in the formal sector.

Therefore,

$u=w_{1} L_{F}+w_{2}\left(\lambda \bar{L}-L_{F}\right)$

Where $\lambda$ is the fraction of $\bar{L}$ determining the size of the union.

$\frac{d u}{d w_{1}}=0 \Rightarrow L_{F}+\left(w_{1}-w_{2}\right) \frac{d L_{F}}{d w_{1}}=0$

Assuming S.O.C is satisfied we get,

$w_{1}=\frac{w_{2}}{1-1 / \epsilon}$

Where $\in=-\frac{\partial L_{F}}{\partial w_{1}} \cdot \frac{w_{1}}{L_{F}}>0$ and for a meaningful $w_{1}, \in>1$

Thus $w_{1}>w_{2}$

Therefore, $w_{1}=\phi\left(w_{2}\right), \phi^{\prime}>0$

We have already derived in the text that

$w_{2}=\phi\left(w_{1}\right), \phi^{\prime}<0$

Analytically one can solve for (2B) and (2C) to get $\left(w_{1}^{*}, w_{2}^{*}\right)$ as equilibrium values. 


\section{Reference:}

Agenor, P.R.,\& Montiel, P.J (1996), Development Macroeconomics, Princeton, NJ: Princeton Univ. Press

Benjamin, N. et al. (2010), Informality, productivity, and enforcement in West Africa: A firm level analysis, IPC (International Policy Center) Working Paper Series Number 100.

Dasgupta, I. and S. Marjit (2006), Evasive reform: Informalization in a liberalized economy with wage-setting unions, in Basudeb Guha-Khasnobis abd Ravi Kanbur (Eds.), Informal Labour Markets and Development. NY: Palgrave-McMillan. pp. 50-70.

Estrin, S. and Mckiewicz, T. (2010), Shadow Economy and Entrepreneurial Entry, IZA (The Institute for the study of labor) Discussion Paper Number 5053.

Goldberg, P. and N. Pavcnik (2003), The Response of the Informal Sector to Trade Liberalization, M.A: NBER working paper No.9443

Helpman, Elhanan (2006), Trade, FDI, and the Organization of Firms, Journal of Economic Literature, Vol. 44 (3), pp 589-630.

Kanbur, Ravi (2009), Conceptualizing informality: Regulation \& Enforcement, India Journal of Labour Economics, Vol. 52 (1), pp 33-42. 
Marcoullier D and L. Young (1995), The black hole of graft: predatory state and the informal economy - American economic Review, Vol. 85 (3), pp 630-646.

Marjit S., S. Ghosh and A.K. Biswas (2007), Informality, Corruption and Trade Reform, European Journal of Political Economy, Vol. 23, pp 777-789.

Marjit S., S. Kar and H. Beladi (2007), Trade Reform and Informal Wages, Review of Development Economics, Vol. 11 (2), pp 313-320.

Marjit S., V. Mukhrejee and M. Kolmar (2006), Poverty, taxation and governance, The Journal of International Trade \& Economic Development, Vol. 15 (3), pp 325-333.

Marjit S. (2003), Economic reform and Informal wage - A General Equilibrium Analysis, Journal of Development Economics, Vol. 72 (1), and pp 371-378.

Rauch, J.E. (1991), Modelling the Informal Sector Formally, Journal of Development Economics, Vol. 35 (1), pp 33-47. 